\title{
Extracorporeal gas exchange in acute lung injury: step by step towards expanded indications?
}

\author{
Rolf Dembinski*1 and Ralf Kuhlen² \\ See related research by Mueller et al., http://ccforum.com/content/13/6/R205
}

\begin{abstract}
Extracorporeal membrane oxygenation (ECMO) is widely accepted as a rescue therapy in patients with acute life-threatening hypoxemia in the course of severe acute respiratory distress syndrome (ARDS). However, possible side effects and complications are considered to limit beneficial outcome effects. Therefore, widening indications with the aim of reducing ventilator induced lung injury (VILI) is still controversial. Consequently, technological progress is an important strategy. Miniaturized ECMO systems are believed to simplify handling and reduce side effects and complications. Mueller and co-workers evaluated such a small-sized device in 60 patients with severe ARDS. They accomplished both the treatment of severe hypoxemia and reduction of VILI, demonstrating feasibility, a moderate rate of severe complications, and a $45 \%$ intensive care survival rate. Although neither randomized nor controlled, this study should encourage others to implement such systems in clinical practice. From a strategic perspective, this is another small but useful step towards implementing extracorporeal gas exchange for the prevention of VILI. It is already common sense that the prevention of acute life-threatening hypoxemia usually outweighs the risks of this technique. The next step should be to prove that prevention of life-threatening VILI balances the risks too.
\end{abstract}

In the previous issue of Critical Care Thomas Mueller and co-workers [1] presented their experience with a miniaturized veno-venous extracorporeal membrane oxygenation (ECMO) system in 60 consecutive patients

\footnotetext{
*Correspondence: rdembinski@ukaachen.de

'Department of Intensive Care Medicine, University Hospital RWTH Aachen,

Pauwelsstraße 30, 52074 Aachen, Germany

Full list of author information is available at the end of the article
}

with severe acute respiratory distress syndrome (ARDS). As a result, miniaturized ECMO was feasible, with a moderate rate of severe complications and $45 \%$ intensive care survival rate. These results have implications for the use of such systems outside the conventional indication of acute life-threatening hypoxemia.

Ever since its original description by Daniel Ashbaugh and co-workers in 1967 [2], hypoxemia in spite of high inspiratory oxygen fractions is the most apparent and acute life-threatening symptom of ARDS [3]. Understandably, ECMO was used solely to optimize blood gas status in the past. However, randomized clinical trials failed to demonstrate beneficial effects of extracorporeal gas exchange on outcome at that time [4,5]. From a present-day perspective these negative results may be best explained by two major drawbacks of those studies: first, the technical standard of those extracorporeal devices was limited; and second, extracorporeal gas exchange was performed as an additional therapy without rigorous adjustment of ventilator settings. Accordingly, two major strategies have been pursued in the past decade: first, to reduce complications of extracorporeal gas exchange devices by technical progress; and second, to make use of this technique to provide lung protective mechanical ventilation. As a result, a recently published study was able to demonstrate at least some beneficial effects on outcome due to a fixed treatment algorithm including ECMO with up-to-date technology [6]. However, it should be noted that this trial - called CESAR (Conventional Versus ECMO for Severe Adult Respiratory Failure) - actually proves beneficial effects due to treatment in a specialized ECMO-capable centre but not due to ECMO per se.

A further increase of effectiveness is suggested by the use of miniaturized ECMO circuits with small-sized but highly effective blood pumps and oxygenators, thereby reducing extracorporeal blood volume, foreign surfaces, contact activation of the coagulation system, inflammatory reactions, and blood trauma [7]. Moreover, these systems offer practical advantages due to simple handling and increased system mobility. With such a miniaturized ECMO system Mueller and co-workers [1] carried out 
interhospital transport in 10 of 60 patients without complications. All 60 patients were connected according to a predefined algorithm when conventional treatment strategies failed to improve gas exchange. Not surprisingly, gas exchange improved significantly due to ECMO treatment and death caused by acute hypoxemia could be prevented entirely. Additionally, tidal volumes were reduced below $6 \mathrm{ml} / \mathrm{kg}$ ideal body weight, thereby accomplishing both aims of ECMO treatment, namely prevention of severe hypoxemia and reduction of ventilator induced lung injury (VILI). In summary, an up-to-date strategy of ECMO treatment was combined with up-to-date ECMO technology.

Therefore, it is astonishing, at first glance, that the survival rate was substantially low compared to other trials $[6,8]$. However, with regard to severity of illness, organ failure, and age, these results appear acceptable. At least, this aspect can not be further evaluated without randomization and controls.

More interestingly, the authors stated that no lifethreatening complications and side effects occurred during the study period. On the other hand, several thrombotic and bleeding complications were reported. Moreover, ECMO implantation was accompanied with resuscitation in two patients and accidental dislocation of a backflow cannula caused life-threatening hypoxia in another patient. Thus, although all these patients could be stabilized immediately, it has to be realized that ECMO therapy still is not safe and easy at all and further studies and developments are still needed to further optimize ECMO technology.

However, the new technology presented by Mueller and co-workers is one step towards this. According to their experience it seems justified to implement the use of miniaturized ECMO systems in clinical practice. In particular, this technique offers practical advantages during transport of ARDS patients. Given the possible advantages of treatment in specialized centers, as has been demonstrated in the CESAR trial, this option should be considered to enable transfer of patients with severe ARDS from peripheral hospitals.

Strictly speaking, scientific evidence for ECMO in ARDS patients with acute life-threatening hypoxemia is still lacking. However, due to ethical considerations, randomized controlled trials are difficult to plan and perform. Therefore, the role of ECMO in this clinical situation will probably never be proved and ECMO is and will be accepted as a rescue therapy.

Scientific evidence for extracorporeal gas exchange in ARDS patients with life-threatening VILI is also lacking, and scarcely anybody would have ethical concerns about withholding extracorporeal gas exchange therapy from these patients today. Therefore, randomized controlled trials are indicated to prove this concept with the lowest possible risk of side effects and complications. In this regard, the study by Mueller and co-workers is a small but useful step forward.

\section{Abbreviations}

ARDS = acute respiratory distress syndrome; $E C M O=$ extracorporeal membrane oxygenation; VILI = ventilator induced lung injury.

\section{Author details}

'Department of Intensive Care Medicine, University Hospital RWTH Aachen, Pauwelsstraße 30, 52074 Aachen, Germany

${ }^{2}$ Department of Intensive Care Medicine, Helios Klinikum Berlin/Buch, Schwanebecker Chaussee 50, 13125 Berlin, Germany

\section{Competing interests}

The authors declare that they have no competing interests.

Published: 11 February 2010

\section{References}

1. Mueller T, Philipp A, Luchner A, Karagiannidis C, Bein T, Rupprecht L, Hilker M, Langgartner J, Zimmermann M, Arlt M, Wenger J, Schmid C, Rieger G, Pfeifer M, Lubnow M: A new miniaturized system for extracorporeal membrane oxygenation in adult respiratory failure. Crit Care 2009, 13:R205.

2. Ashbaugh DG, Bigelow DB, Petty TL, Levine BE: Acute respiratory distress in adults. Lancet 1967, 2:319-323.

3. Bernard GR, Artigas A, Brigham KL, Carlet J, Falke K, Hudson L, Lamy M, LeGall JR, Morris A, Spragg R: The American-European Consensus Conference on ARDS. Definitions, mechanisms, relevant outcomes, and clinical trial coordination. Am J Respir Crit Care Med 1994, 149:818-824.

4. Zapol WM, Snider MT, Hill JD, Fallat RJ, Bartlett RH, Edmunds LH, Morris AH, Peirce EC, Thomas AN, Proctor HJ, Drinker PA, Pratt PC, Bagniewski A, Miller $\mathrm{RG} J \mathrm{~J}$ : Extracorporeal membrane oxygenation in severe acute respiratory failure. A randomized prospective study. JAMA 1979, 242:2193-2196.

5. Morris AH, Wallace CJ, Menlove RL, Clemmer TP, Orme JF Jr, Weaver LK, Dean NC, Thomas F, East TD, Pace NL: Randomized clinical trial of pressurecontrolled inverse ratio ventilation and extracorporeal $\mathrm{CO} 2$ removal for adult respiratory distress syndrome. Am J Respir Crit Care Med 1994, 149:295-305

6. Peek GJ, Mugford M, Tiruvoipati R, Wilson A, Allen E, Thalanany MM, Hibbert CL, Truesdale A, Clemens F, Cooper N, Firmin RK, Elbourne D: Efficacy and economic assessment of conventional ventilatory support versus extracorporeal membrane oxygenation for severe adult respiratory failure (CESAR): a multicentre randomised controlled trial. Lancet 2009, 374:1351-1363.

7. Dembinski R, Kopp R, Henzler D, Hochhausen N, Oslender N, Max M, Rossaint $R$, Kuhlen R: Extracorporeal gas exchange with the DeltaStream rotary blood pump in experimental lung injury. Artif Organs 2003, 27:530-536.

8. Brogan TV, Thiagarajan RR, Rycus PT, Bartlett RH, Bratton SL: Extracorporeal membrane oxygenation in adults with severe respiratory failure: a multicenter database. Intensive Care Med 2009, 35:2105-2114.

doi:10.1186/cc8837

Cite this article as: Dembinski R, Kuhlen R: Extracorporeal gas exchange in acute lung injury: step by step towards expanded indications? Critical Care 2010, 14:116. 